\title{
Effect of salbutamol on oxygen saturation in bronchiolitis
}

\author{
Ling Ho, G Collis, L I Landau, P N Le Souef
}

\begin{abstract}
Inhaled sympathomimetic agents are often used in bronchiolitis with little objective evidence of benefit. The arterial oxygen saturation $\left(\mathrm{SaO}_{2}\right)$ reflects the adequacy of ventilation-perfusion balance. The aim of the current study was to determine the effect of inhaled salbutamol on $\mathrm{SaO}_{2}$. In a randomised, double blind study, 21 infants, admitted with bronchiolitis positive for respiratory syncytial virus, had continuous $\mathrm{SaO}_{2}$ measurements made before and after nebulised salbutamol or placebo. $\mathrm{SaO}_{2}$ was recorded over 30 minutes for a baseline, then during the 10 minutes of first nebulisation with either salbutamol or saline, then over 30 minutes after nebulisation, the 10 minutes of second nebulisation with the alternate regime, and another $\mathbf{3 0}$ minutes after this second nebulisation. Desaturation occurred after salbutamol and saline nebulisation. The fall in $\mathrm{SaO}_{2}$ with salbutamol was seen whether infants received it as the first or second nebulisation. The fall in $\mathrm{SaO}_{2}$ after saline was seen when given first, but not when given after salbutamol. The decrease in $\mathrm{SaO}_{2}$ was greater and more prolonged with salbutamol than with saline. Routine nebulised aerosol sympathomimetic treatment during acute bronchiolitis cannot be recommended.
\end{abstract}

Acute bronchiolitis in infants is a common cause of hospitalisation. The use of bronchodilators in respiratory viral bronchiolitis has been controversial. ${ }^{1-3}$ Studies during the acute and the recovery phase of bronchiolitis have shown variable change in respiratory resistance and work of breathing with some demonstrating increased hypoxia after a single dose of nebulised sympathomimetic. ${ }^{1-24}$ Improved conductance in some infants has been reported. ${ }^{9}$ Conflicting results from the limited measurements possible in this young age group and entrenched preconceptions still lead to uncertainty about the role of bronchodilators in the treatment of acute bronchiolitis.

Arterial oxygen saturation $\left(\mathrm{SaO}_{2}\right)$ is the most relevant outcome measurement of the adequacy of ventilation and ventilation-perfusion balance. We measured the effect of aerosol sympathomimetics on continuous $\mathrm{SaO}_{2}$ measurements in infants with acute viral bronchiolitis.

\section{Subjects and methods}

SUBJECTS

Children admitted with cough and wheeze due to acute bronchiolitis were entered into the study within five days of admission. All children had no prior history of respiratory symptoms, the clinical findings of hyperinflation with wheeze and crackles on auscultation, and respiratory syncitial virus isolated by immunoflourescence of a postnasal aspirate. Severely ill children and those with associated chronic disabilities were excluded. Approval was obtained from the hospital's medical ethics committee and parental consent was obtained. The children were studied while quiet without sedation.

We studied 21 infants; there were 11 boys and 10 girls with a mean age of 3 months (range 3 weeks -6 months) and mean weight $5.6 \mathrm{~kg}$ (range 3-6 kg). Fifteen were breast fed and 14 had a history of parental smoking. None had a history of asthma in first degree relatives. Three of the children were receiving supplemental oxygen.

\section{VARIABLES}

$\mathrm{SaO}_{2}$ was measured using a pulse oximeter (Nellcor N200E) with finger sensor attached to the patient and the output recorded on a chart recorder. Electrocardiogram leads were applied to check the heart rate and to detect arrhythmias. Heart rate, an electrocardiogram, and $\mathrm{SaO}_{2}$ were monitored continuously on the chart recorder paper. Observations were noted of movement, crying, and coughing throughout the 110 minutes. In those receiving supplemental oxygen, oxygen was continued in the same inspired concentration as before the study.

\section{PROTOCOL}

Subjects were studied using a double blind, random allocation, crossover design. Continuous $\mathrm{SaO}_{2}$ measurements were made over 110 minutes before and after nebulised salbutamol $(2.5 \mathrm{mg} / 2 \mathrm{ml})$ or placebo $(2 \mathrm{ml}$ normal saline $)$. Measurements were made during 30 minutes baseline, 10 minutes of first nebulisation, 30 minutes observation, 10 minutes of second nebulisation, and 30 minutes observation. Nebulisations were given using an Airlife jet nebuliser run from a compressed gas supply with a flow of $61 /$ minute. For the three patients on oxygen, the concentration of oxygen was checked with an oxygen analyser (Teldyn), and maintained at the prestudy level using a Bird oxygen blender which could adjust the oxygen mixture and maintain a flow of 61 /minute.

The $\mathrm{SaO}_{2}$ tracing was analysed using a digitising 
graphic tablet and a morphometric program on an Apple $\mathrm{E}$ computer. The average $\mathrm{SaO}_{2}$ for each minute was determined from the graph using area under the curves for each minute. The mean $\mathrm{SaO}_{2}$ for baseline was obtained over the first 30 minutes. The means of the 10 minute nebulisation period and mean of 5 minutes epochs after nebulisation for each patient were taken. Readings beyond 25 minutes after the second nebulisation could not be analysed due to interference from excessive movement in the majority of patients.

The results of the patients first given salbutamol or saline were analysed with a two way analysis of variance and the significance of change in desaturation from baseline determined with Dunnett's q test. The results of patients given salbutamol as the second nebulising solution were analysed with a one way repeated measure analysis of variance. No further statistical analysis was performed on patients receiving saline second as there was some persistent effect of salbutamol used as the first nebulising solution.

The periods of maximum desaturation from baseline, the times to reach maximum desaturation, and the times taken for recovery to baseline saturation for each group of patients

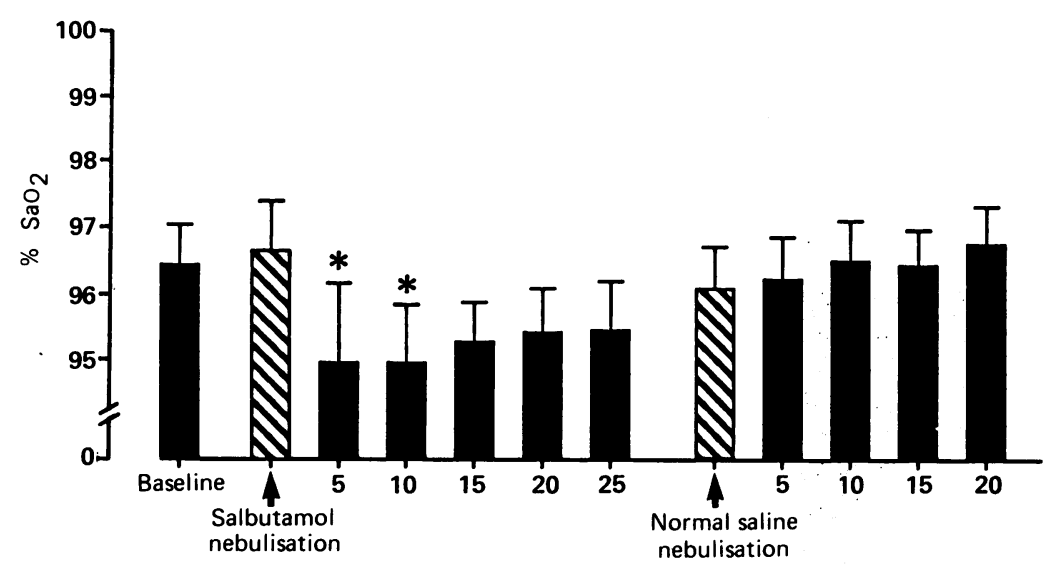

Time interval $(\mathrm{min})$

Figure $1 \mathrm{SaO}_{2}$ after an initial salbutamol nebulisation with a saline nebulisation after 30 minutes; "significant decrease, $p<0 \cdot 05$.

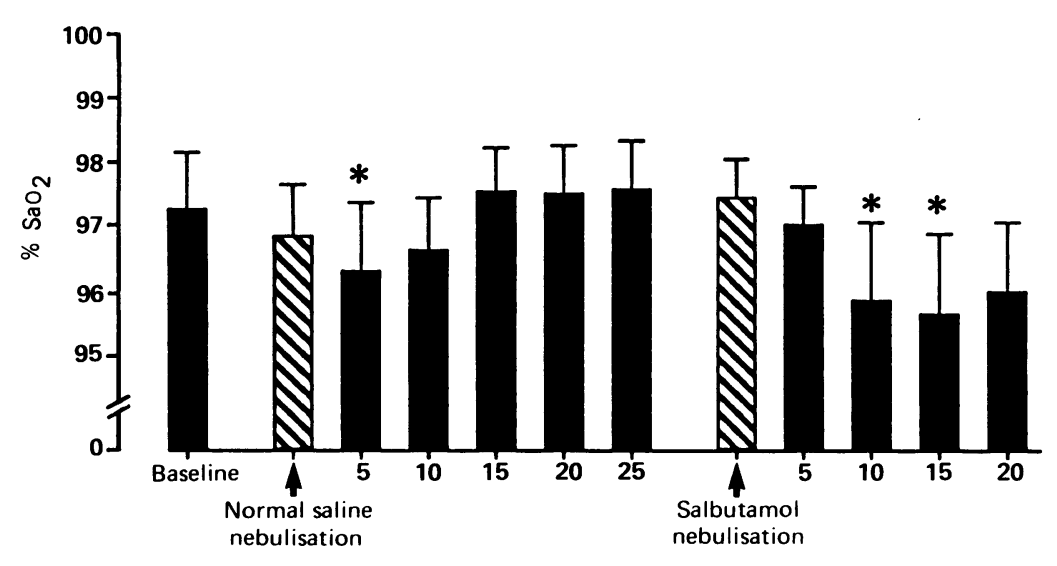

Time interval $(\mathrm{min})$

Figure 2 Sas, after an initial saline nebulisation with a salbutamol nebulisation after 30 minutes;" significant decreasc, $p<0 \cdot 05$. were studied using a Kruskal-Wallis test. The differences betwen groups were analysed with $\chi^{2}$ or Mann-Whitney non-parametric test where appropriate.

\section{Results}

For the 13 patients receiving salbutamol first there was a desaturation from mean baseline percent $\mathrm{SaO}_{2}$ of 96.4 and 96.6 (during nebulisation) to $95 \cdot 0,95 \cdot 0,95 \cdot 3,95 \cdot 4$, and $95 \cdot 4$ at each five minute epoch after nebulisation (fig 1). A most significant decrease occurred five and 10 minutes after salbutamol nebulisation $(p<0.05)$. After saline as the second nebulisation, there was no further desaturation with an $\mathrm{SaO}_{2}$ of $96 \cdot 1$ during nebulisation to $96 \cdot 2,96 \cdot 5,96 \cdot 4$, and 96.8 after nebulisation.

The eight patients receiving saline first also showed desaturation from a baseline $\mathrm{SaO}_{2}$ of $97 \cdot 2$ and $96 \cdot 8$ (during nebulisation) to $96 \cdot 3$, $97 \cdot 6,97 \cdot 5$, and $97 \cdot 5$ for each five minute epoch after nebulisation, a significant drop being recorded five minutes after saline nebulisation (fig 2). However, the drop in $\mathrm{SaO}_{2}$ was again more noticeable after salbutamol given as the second nebulisation, with $\mathrm{SaO}_{2}$ of $97 \cdot 4$ during nebulisation and levels of $97 \cdot 0,95 \cdot 9,95 \cdot 6$, and 95.9 for each five minute epoch after nebulisation. A significant drop was seen 10 and 15 minutes after nebulisation.

Eleven of the 13 patients given salbutamol first had a desaturation from baseline after salbutamol. All eight given salbutamol second desaturated after this nebulisation. The maximum fall in $\mathrm{SaO}_{2}$ from baseline was greater in those who received salbutamol first and those who received salbutamol after saline than those who received saline first (fig 3). Although there was no significant difference between groups for the median maximum falls in $\mathrm{SaO}_{2}$ after the first nebulisation, nine of 13 had a maximum fall in $\mathrm{SaO}_{2}$ greater than $4 \%$ after salbutamol as the first nebulisation compared with two of eight after saline as the first nebulisation $(p<0.05)$.

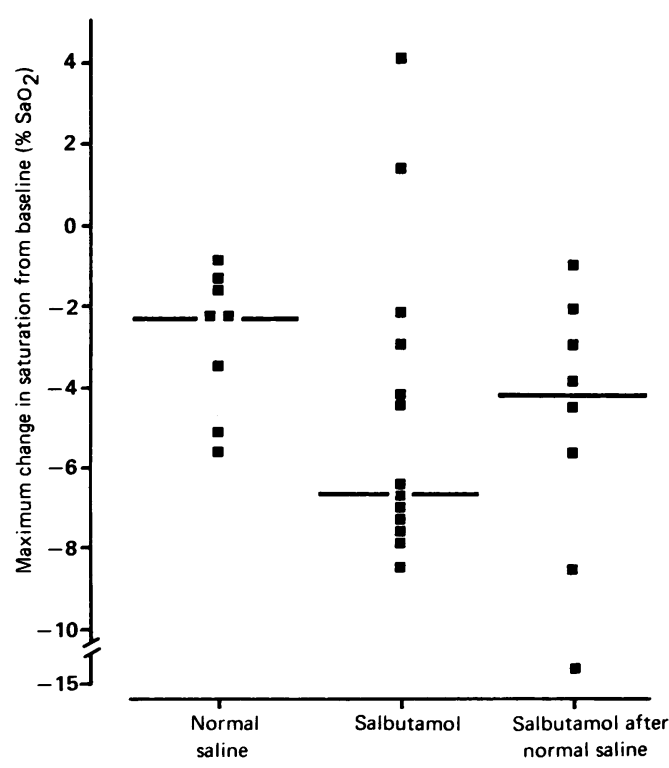

Figure 3 Maximum change in $\mathrm{Sa}_{2}$, after saline

nebulisation, salbutamol nebulisation, and salbutamol nebulisation 30 minutes after a previous saline nebulisation. Medians shown. 


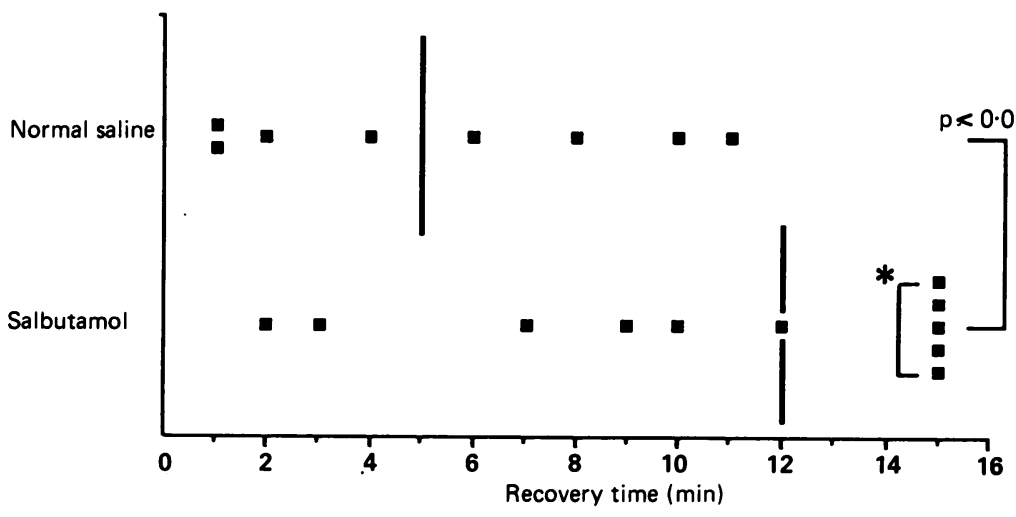

Figure 4 Time taken for $\mathrm{SaO}_{2}$ to return to baseline after saline nebulisation and salbutamol nebulisation. "Denotes subjects where Sa( ${ }_{2}$ had not returned to baseline before start of second nebulisation; they were allocated a recovery time of 15 minutes. Medians shown.

Four of the eight who had salbutamol as the second nebulisation showed a maximum fall in $\mathrm{SaO}_{2}$ greater than $4 \%$. Median time to reach maximal desaturation after the first nebulisation was not significantly different between the salbutamol and saline groups (9-10 minutes and five minutes respectively).

The 11 patients given salbutamol who desaturated took a median of 12 minutes to recover while the other eight patients given saline who desaturated took five minutes to recover (fig 4). The time required for patients given salbutamol to recover was significantly longer $(p<0.05)$.

\section{Discussion}

This study has demonstrated significant falls in $\mathrm{SaO}_{2}$ in infants with mild to moderate bronchiolitis given nebulisations of either salbutamol or saline with salbutamol having a more profound effect. Previous studies reporting the effect of bronchodilators in infants with bronchiolitis have used clinical scores or lung function measurements as outcome measures. ${ }^{5} 9^{13-21}$ Most have shown no improvement and some reported deterioration in lung function after bronchodilator. ${ }^{72} 21$ Soto $e t$ al found increased conductance in about $30 \%$ but the clinical significance was uncertain. ${ }^{9}$ Reynolds measured arterial blood gas tensions but repeated measures could not be taken. ${ }^{22}$ Some have argued that measurements used have not been appropriate to document the potential benefit that is sometimes clinically apparent. We reasoned that $\mathrm{SaO}_{2}$ is the clinically significant outcome measure of the adequacy of ventilation and perfusion in this condition and that oximetry is a useful non-invasive method to document the effect of bronchodilators on $\mathrm{SaO}_{2}$. We have therefore used oximetry to measure the response to nebulised salbutamol over $\mathbf{3 0}$ minutes.

The study was a randomised, double blind, crossover design where patients acted as their own control. Chloral hydrate has been used in previous studies. ${ }^{7} 131421$ As desaturation may occur with sedation in moderately sick infants with bronchiolitis no sedation was used in this study. Although some infants had coughing spells, they were not prolonged and did not limit measurements. We have also selected a group of infants aged under 6 months with proved respiratory syncytial viral infection and no previous wheezing or other illness to avoid confounding by case mix. There is considerable confusion about the diagnosis of asthma in this. age group and its association with bronchiolitis.

In this study we have demonstrated that infants have significant desaturation when given salbutamol first or after saline nebulisation. Saline nebulisation also caused desaturation; however, the fall in $\mathrm{SaO}_{2}$ was greater and took longer to recover with salbutamol than with saline. The bronchodilator effect after salbutamol inhalation starts at 5-10 minutes and can last up to two to four hours. ${ }^{25}$ The desaturation noted occurred at the time of maximal action of salbutamol and was consistent whether salbutamol was given first or second.

Desaturation was also seen with saline nebulisation, but the effect was smaller, and was more transient than for salbutamol. We assume that the desaturation with saline was related to disturbance of the baby. The mechanism of action of the salbutamol is unclear, but may be due to airway narrowing, vascular dilation leading to shunting, or both. The time course is different to that usually seen in adults with presumed shunting after salbutamol and we would suggest that the salbutamol aerosol also appears to impair ventilation in these infants by an irritant or osmotic effect of the aerosolised nebulising solution..$^{20}$

Although the median fall in $\mathrm{SaO}_{2}$ was small, there were some infants who demonstrated a drop of $10 \%$ or more. These infants had mild disease at the time studied and this effect in an infant with severe disease could be significantly detrimental. Some previous studies have noted hypoxia $^{7}$ and deterioration in lung function ${ }^{14} 21$ after bronchodilators in wheezy infants.

Nebulisations do not benefit infants with bronchiolitis who are already distressed. Salbutamol aggravates this process and cannot be recommended. In the event of an uncertain clinical diagnosis when assessment of a response to salbutamol is thought indicated, monitoring with pulse oximetry should be used.

1 Lenney W, Milner AD. At what age do bronchodilator drugs work? Arch Dis Child 1978;53:532-5.

2 Wilson NM. Wheezy bronchitis revisited. Arch Dis Child 1989;64:1194-9.

3 Milner AD, Murray $M$. Acute bronchiolitis in infancy: treatment and prognosis. Thorax 1989;44:1-5.

4 Spier S, Lapierre JG, Lamare A. Response to salbutamo during a first or second episode of wheering in infancy. $A m$ Rev Respir Dis 1985;131:A259.

5 Lenney W, Milner AD. Alpha and beta adrenergic stimulants in bronchiolitis and whee $y$ bronchitis in children under 18 months of age. Arch Dis Child 1978;53:707-9.

6 Radford M. Effect of salbutamol in infants with whee\%y bronchitis. Arch Dis Child 1975;50:535-8.

7 Prendiville A, Rose A, Maxwell DI, Silverman M. Hypoxaemia in wheezy infants after bronchodilator treatment. xaemia in whee'y infants after bron
Arch Dis Child 1987;62:997-1000.

8 Seidenberg J, Masters IB, Hudson I, Olinsky A, Phelan PD. Disturbance in respiratory mechanics in infants with Disturbance in respiratory mechanic
bronchiolitis. Thorax 1989;44:660-7.

9 Soto M, Sly PD, Uren E, Taussig I.M, Landau L.I. Bronchodilator response in acute viral bronchiolitis. Pediat Bronchodilator response in acute viral bronchiolitis. Pediat
Pulmonol 1985;1:85-90. Reynolds

Reynolds EOR, Cook CD. Treatment of hronchiolitis. Y Pediatr 1963;63:1205-7.

11 Anonymous. Acute bronchiolitis in infancy: treatment and prognosis. [Editorial.] Thorax 1989;44:1-5.

12 Silverman M. Bronchodilators for whec/y inlants? Arch I is Child 1984;59:84-7. 
13 Phelan PD, Williams HE. Sympathomimetic drugs in acute viral bronchiolitis. Their effect on pulmonary resistance. Pediatrics 1969;44:493-7.

14 Hughes D, LeSouef PN, Landau LI. Effect of salbutamol on respiratory mechanics in bronchiolitis. Pediatr Res 1987;22: 83-6.

15 Rutter N, Milner AD, Hiller EJ. Effect of bronchodilators on respiratory resistance in infants and young children with bronchiolitis and wheezy bronchitis. Arch Dis Child 1975; 50:719-22.

16 Milner AD, Stokes GM, Hodges IBC, Henry RC, Elphick MC. Nebulised therapy in acute severe bronchiolitis in infancy. Arch Dis Child 1983;58:279-83.

17 Darcy I, Lowell G, Lister H, McCarthy P. Wheezing in infants: the response to epinephrine. Pediatrics 1987;79: infants:

18 Mallol J, Munoz R, Puppo H, et al. Effects of nebulised fenoterol associated with ipratropium or steroids on the heart rate of infants under one year of age with acute wheezing. Pediatr Pulmonol 1987;3:83-5.
19 Mallol J, Munoz R, Pullo H, et al. Use of nebulized bronchodilators in infants under one year of age: analysis of four forms of therapy. Pediatr Pulmonol 1987;3:298-303.

20 O'Callaghan C, Milner AD, Swarbrick A. Paradoxical deterioration in lung function after nebulised salbutamol in deterioration in lung function after nebulis
wheezy infants. Lancet 1986;ii:1424-5.

21 Prendiville A, Green S, Silverman M. Paradoxical response to nebulised salbutamol in wheezy infants assessed by partial expiratory flow-volume curves. Thorax 1987;42:86-91.

22 Reynolds EOR. Arterial blood gas tension in acute disease of lower respiratory tract in infancy. $B M \mathcal{F} 1963 ; \mathrm{i}: 1192$.

23 Wohl MEB, Chernick V. Bronchiolitis. Am Rev Respir Dis 1978;118:759-81.

24 Tal A, Bavilski C, Yohai D, Boarman JE, Gorodischer R, Moses SW. Dexamethasone and salbutamol in the treatment of acute wheezing in infants. Pediatrics 1983;71:13-7.

25 Reynolds JEF, ed. Sympathomimetics. Martindale. The extra pharmacopoeia. 29th Ed. London: Pharmaceutical Press, 1989:1480-3.

Birth weight and the health of nations

Professor Eva Alberman in her presidential address to the section of epidemiology and public health of the Royal Society of Medicine (Fournal of the Royal Society of Medicine 1991;84:257-60) pointed to the value of birthweight statistics as a measure of the health status of a population.

Birth weight is the most powerful predictor of infant survival affecting both neonatal and postneonatal components of infant mortality. Usually the lowest infant mortality is found in babies whose birth weights are about 500 to $1000 \mathrm{~g}$ above the mode, although there is a slight increase in mortality at very high birth weights. It is suggested that the disparity between optimal and modal birth weight may be due to the birthweight curve being displaced to the left by the presence at the lower end of the distribution of babies with a pathological cause for their low weight but it is difficult to isolate 'normal' babies to define a pure 'normal' distribution.

Clearly there are biological factors which affect both birth weight and mortality. Girls tend to have a slightly lower birth weight and they have a lower infant mortality for all birth weights. Ethnic differences in birth weight and mortality are probably partly genetic but largely environmental. In the United States the modal birth weight for black babies is about $400 \mathrm{~g}$ less than for white. Below a birth weight of about $2000 \mathrm{~g}$ infant mortality is less in blacks presumably because small black babies are more 'normal' or more mature than small white babies. At birth weights above $3000 \mathrm{~g}$ infant mortality in blacks exceeds that in whites. The findings are similar in relation to maternal smoking: at low birth weights the babies of smoking mothers have a slightly lower mortality that those of non-smokers but babies of smoking mothers who weigh over $3000 \mathrm{~g}$ at birth have a higher first year mortality than those of the same birth weight whose mothers do not smoke.

In England and Wales the mean birth weight up to 1986 had changed little over the last 30 years being $3315 \mathrm{~g}$ in $1958,3302 \mathrm{~g}$ in 1970 , and $3318 \mathrm{~g}$ in 1986 but the percentage of babies weighing $3500 \mathrm{~g}$ or more at birth rose from $35.9 \%$ in 1983 to $38.6 \%$ in 1989 . Since 1986 there appears to have been some increase in mean birth weight which has been most marked in the less privileged social classes.

A further decrease in maternal smoking and improved maternal health and nutrition among disadvantaged groups would probably lead to higher birth weights and lower infant mortality. 